\title{
Influence of sample slenderness and boundary conditions in triaxial test - a review
}

\author{
Elena Peri*, Lars Bo Ibsen, and Benjaminn Nordahl Nielsen \\ Department of Civil Engineering, Aalborg University, Denmark
}

\begin{abstract}
In the past decades an extensive work was done in order to improve the performance and increase the reliability of triaxial testing. Among the several changes made in order to solve the inaccuracies of the traditional test configuration, two of them are discussed in this paper: the sample slenderness [in other words, the $\mathrm{H} / \mathrm{D}$ ratio] and the introduction of smooth end platens instead of the rough ones. By using $\mathrm{H} / \mathrm{D}=1$ and not the usual $\mathrm{H} / \mathrm{D}=2$ ratio, the formation of a single line-rapture and the bulge shape seem prevented. The smooth ends decrease the restrain at the top and bottom of the sample. From a theoretical point of view the effects of these changes are clear, but experimentally, the results coming from various studies are contradictory. The purpose of this paper is to elucidate the previous findings on the topic, including both laboratory and FEM modelling test programs.
\end{abstract}

\section{Introduction}

The triaxial test is a standard procedure, useful in almost all the geotechnical designs thanks to its versatility. A sample response able to reflect more precisely the true stress-strain behaviour of a soil implies a more reliable test interpretation.

According to Lee [1], Taylor [2] stated how the application of usual fixed ends on samples with $H / D=1.5$ 3.0 could give reliable results. Starting from this study, the adoption of different end restraints and H/D ratios was ignored until the 60's.

As recommended by Eurocode and employed worldwide, the triaxial test set-up has been commonly related to a sample slenderness equal to $H / D=2 \div 2.5$ and to rough end caps, resulting from the use of filter stones with the same diameter as the sample. On the contrary, the Danish geotechnical tradition makes use of samples with $\mathrm{H} / \mathrm{D}=1$ and smooth (lubricated and enlarged) caps. This choice is supposed to guarantee a more homogeneous behaviour and less disturbance in the sample. Several authors support this theory i.e. [3-8].

After the first extensive works on the triaxial testing procedure were published $[9,10]$, many evolutions were suggested. Several authors agree on the fact that the traditional triaxial test leads to inaccuracies in detecting both strength and deformation parameters. Samples tested with rough ends and $\mathrm{H} / \mathrm{D}=2$ often show an increase in volume at the mid-height and tend to the profile of a barrel [11-14]. It is also possible to notice a line rapture crossing the sample. As soon as the failure occurs in such shear bands, the strains recorded are no longer representative of the behaviour of the soil. This because the soil properties measured refer only to the soil surrounding this area. Main cause of these non-homogenous response, volume change and bulging effect is the friction at the end platens that acts as a restraint on the sample [12, 15].

Failure conditions are a function of both H/D ratio and end boundaries [16] and an understanding of the separate direct influences of these two factors is quite complicated. Several test programs try to evaluate and quantify the roughness of the end platens. Less investigations test a sample slenderness different than $H / D=2$. The $H / D$ ratio has been recognised has main factor of influence on the stress, not the absolute dimensions of the sample itself [17]. Rowe and Barden [12] and Bishop and Green [18] were among the first authors who tested samples with slenderness $H / D=1$. They agree that sand samples with $\mathrm{H} / \mathrm{D}=1$ and smooth ends show a cylindrical shape instead of the barrel profile. Moreover, samples tested in this way present higher axial strains than samples with the traditional configuration. Fig 1 shows the theoretical homogeneous stress state reached when $H / D=1$ and smooth ends are employed [19]; instead inhomogeneous stress condition (Fig. 1b) and single line failure (Fig. 1c) occur when different set-up are applied.

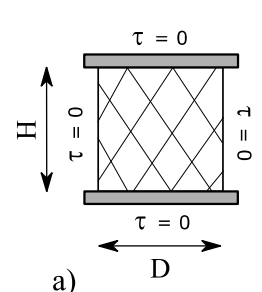

a)

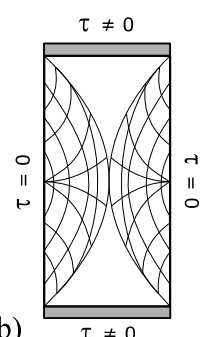

b)
Fig 1. a) sample with smooth ends and $H / D=1$, b) tall samples with rough ends imply dead zones at the ends, c) tall samples and smooth ends cause a single line failure.

\footnotetext{
${ }^{*}$ Corresponding author: epe@ $@$ civil.aau.dk
} 


\subsection{Present work}

From a theoretical point of view, the reasons behind the combined adoption of $\mathrm{H} / \mathrm{D}=1$ and smooth ends are clear, but experimentally, results from different studies are contradictory. The aim of the present work is to elucidate the implications of these two factors: the H/D ratio and the adoption of smooth ends. This literature review is intended to be a starting point of a complete test program, successful in comparing the effect of each factor and in evaluating its implication.

\section{Experimental work}

Many authors discussed triaxial test results in the past decades and the number of experimental test run is wide. But different test programs are not always easy to compare with each other. Various set-up of the test itself (drained or undrained tests, different saturation level or procedure), adjustments or alterations in the equipment (modification in the platens, membranes and cell), sample size and preparation techniques make each experimental programme unique and an objective comparison between programmes difficult to make.

It is problematic to separate the effect of the H/D ratio from the effect of the ends, unless the experimental design takes into account a wide variety of combination. Moreover, the number of tests run are often not enough to be statistically relevant. In the next paragraphs results are presented keeping in mind these assumptions.

\subsection{Sample slenderness effect}

Rutledge [20], discussing previous findings [2], summarized that reliable results can be obtained from samples with a H/D ratio between 1.5 to 3 and different sample shapes do not imply significant differences. Based on these early works, the $\mathrm{H} / \mathrm{D}=2$ ratio become the usual geometry. Only later, the $\mathrm{H} / \mathrm{D}=1$ ratio started to be frequently associated with a more stable behavior. Bishop and Green [18] report how, after the test, the sample with $\mathrm{H} / \mathrm{D}=1$ and smooth ends still showed a cylindrical shape. Also Lee [21] connects an higher H/D ratio to the nonuniform conditions inside the sample, and therefore with premature failure. Jacobsen [3] states how $\mathrm{H} / \mathrm{D}=1$ prevents the formation of shear bands. The observations above were made at the naked eyes, but thanks to x-ray tomography scan, the presence of shear-band like events seems not to be excluded in any case, even at small strain and when $\mathrm{H} / \mathrm{D}=1$ [22].

Several test programs assert that a $H / D=1$ ratio ensures a more homogenous stress and strain distribution and presents less bulging effect than samples with $\mathrm{H} / \mathrm{D}=2[4,8,16,23,24]$.

But impending the formation of shear bands could have different interpretations. For example, with a $H / D=2$ ratio the shear band is free, while it is impeded and delayed with $\mathrm{H} / \mathrm{D}=1$ [25]. According to Moores and Hoover [26] the optimal H/D ratio is related to the friction angle of the soil tested and a sample height allowing two complete cones of failure to have space should be preferred.

\subsubsection{Effects on granular soils}

Carrying out one of the first extensive test programs investigating sample slenderness and ends effect on sand, Bishop and Green [18] find out that rough ends increase the soil strength, but this effect is more significant when $H / D=1$ than $H / D=2$. In fact, samples with smooth ends and $H / D=1$ display larger axial strains and larger dilation at failure. Regarding the angle of shearing resistance, an appreciable difference is not noted if perfect lubrication is provided. Larger bulging effect in higher samples and similar friction angle between different H/D ratio (when the same kind of lubrication is applied) are reported by Tatsuoka et al. [24] and Raju et al. [27]. Instead, Ladanyi and Arteau [28], investigating frozen sand in unconfined compression tests, find out that a lower $\mathrm{H} / \mathrm{D}$ ratio is related to higher strength. Also Colliat-Dangus et al. [23] report a slightly higher friction angle for samples with smooth ends and $\mathrm{H} / \mathrm{D}=1$ than for those with smooth ends and $\mathrm{H} / \mathrm{D}=2$.

Generally, the stress-strain curve in the sample with $\mathrm{H} / \mathrm{D}=1$ and smooth ends is smoother than in the other configuration. When samples with $\mathrm{H} / \mathrm{D} \geq 1.5$ are tested the stress-strain curve appears more brittle [28]; as well as the axial strains-to-failure after failure are shorter $(5-7 \%$ with $\mathrm{H} / \mathrm{D}=2.5$ and $9-10 \%$ with $\mathrm{H} / \mathrm{D}=1$ ) [29]. Even if the peak strength value does not seem significantly different between the two configurations, samples with $H / D=1$ and smooth ends appear to give more consistent results [23, 29].

Regarding the volumetric response, some authors find a higher percentage of dilation in sample where $\mathrm{H} / \mathrm{D}=1$ $[18,27,29]$; instead, others authors report how the H/D ratio does not have a significant influence on volumetric strain or the peak dilatancy rate either [23].

\subsubsection{Effects on cohesive soils}

Among the first authors testing different $\mathrm{H} / \mathrm{D}$ ratios on clay, Olson and Campbell [13] do not detect a big influence of the $\mathrm{H} / \mathrm{D}$ ratio on the shearing strength. Studying the way of rupture, Lade [30] observes a line failure only in the traditional samples and not in the ones with smooth ends and $\mathrm{H} / \mathrm{D}=1$. Moreover, the strength properties are slightly higher for the traditional samples, due to the effect of end restraint. The stress-strain curve for the samples with low H/D is smoother as well as the strains after failure are larger. Jacobsen [31] investigated the properties of Moraine clay. While the friction angle is almost the same, the cohesion value is higher in sample with $H / D=1$ than with $H / D=2$. More recently, Güneyli and Rüşen [32] run unconfined compression tests on different kinds of clay samples with $H / D=0.5-3.0$. This study reports a higher unconsolidated undrained shear strength for the samples with lower H/D. Augustesen et al. [33] carried out limited numbers of tests and state that smooth ends combined with $\mathrm{H} / \mathrm{D}=1$ guarantee homogeneous stress and strain condition but do not eliminate completely 
the barrel effect. About the undrained shear strength, no big difference was reported between the different H/D ratios. This similarity can be due, as shown, to the not enlarged - so not efficient - adopted platens.

In general, several results agree on associating the $\mathrm{H} / \mathrm{D}=1$ ratio with a more homogeneous stress-strain condition and failure, a reduced barrel shape and larger axial and volumetric strains. The majority also agree on higher strength properties when $\mathrm{H} / \mathrm{D}=1$, while the friction angle is found to be not much different than in samples with $\mathrm{H} / \mathrm{D}=2$.

\subsection{End platens effect}

End platens have been refined and improved by several authors. Larew [34], Rowe [35], Blight [36] and later Goto and Tatsuoka [16] developed different kinds of end platens. Among these, Rowe's method is recognized as the most effective one to guarantee smooth ends [37]. It consists in silicon grease coating the platen covered with rubber sheet. The enlarged ends with greased membrane designed by Rowe and Barden [12] became a well-known system of minimizing end disturbance. On the other hand, using layers of membrane and grease could lead to bedding effect and so errors in detecting the right axial displacement [10], [11].

\subsubsection{Effect on granular soils}

After the above mentioned experiments, many others test programs followed. Some authors state that lubricated ends are needed to guarantee uniform stress and strain conditions inside the sample [14, 38-43]. There is also a general agreement on how rough ends lead to increased strength properties. Dresher and Vardoulakis [38] found how rough ends are a source of overestimated, so unsafe, friction angle. Raju et al. [27] agree, recording an higher friction angle in tests with rough ends. In addition, with lubricated ends, stress and deformation are more uniform, the results are more consistent and the test can continue up to an axial strain of about 18-20\%. Later, also Lee [44] finds an higher friction angle by using rough ends $\left(3^{\circ}\right.$ in the drained tests and $1^{\circ}$ in the undrained ones). In addition, lubricated ends lead to a noticeable higher volumetric and axial increase at higher strains. Recently, Omar and Sadrekarimi [45] assess that rough ends could lead to an average of $10 \%$ overestimation of the undrained shear strength and $3.6^{\circ}$ of critical friction angle in sand. In addition, the barrel-shape is the most significant source of error affecting these two parameters. On the contrary, according to Lee [21], the sand strength increase by about $15-20 \%$ for static tests and $25-40 \%$ for cyclic tests when frictionless platens are used. Other authors who discussed cycling tests on sand are Ibsen and Lade [19]. Testing a sample with $H / D=2$ and fixed ends results in a higher friction angle and smaller axial strain at failure. Other experiments proved that smooth ends effect is negligible. Goto and Tatsuoka [16] test the effect of lubricated ends and sample slenderness on sand. In dense samples with $\mathrm{H} / \mathrm{D}=2$, the angle of internal friction is just $1^{\circ}$ larger with rough ends than when smooth ends are used. For loose sample is even less.

Several of the above mentioned papers are discussed in Saada and Townsend's work [46].

\subsubsection{Effect on cohesive soils}

While Casagrande and Poulos [47] do not detect relevant difference in applying enlarged smooth caps in long term tests, Barden and McDermott [39] stress their importance and present a broad test program on clays. The pore pressure variation during the test is used as an indicator of non-uniformity of test condition. Smooth ends, in combination with $\mathrm{H} / \mathrm{D}=1$, are able to guarantee a cylindrical shape till $20 \%$ of axial deformation. According the results on undrained triaxial tests on clay by Duncan and Dunlop [48], the strength increase due to the use of rough ends is equal to $8 \%$. But the effect of lubricated ends is not as significant as the type of test (triaxial and plane strain test are compared by Duncan and Dunlop). Olson and Campbell [13], testing kaolinite, find a negligible effect on the total-stress internal friction angle; instead, the effective-stress angle is reduced by about $3^{\circ}$, when lubricated ends are used. More recently, Sachan [49], performing undrained tests on kaolinite, found an increase of $5^{\circ}$ in the friction angle while using smooth platens instead of rough ends.

\subsubsection{Effect on volume response}

There are contradictory opinions regarding the effect of ends on volume change. Raju et al. [27] report a lower or similar increment in volumetric strains in dry sand tests with smooth ends, depending on the initial density. Other authors $[48,50]$ state how the volume change is bigger for lubricated samples than for the ones with rough ends, at the same stress level, but when the axial strain is the same, it is the unlubricated sample that shows higher compressive volume change. Roy and Lo [14] claim there is no big difference in the total volume change in the granular material tested. But the authors precise how this is maybe due to the fact that the value recorded is indeed a total value, so it does not take into account any difference between volume change near the ends and volume change at the mid-height, where very high volume increase is caused by the barreling effect.

To summarize, many authors agree that the shear strength detected is higher with rough ends than smooth ones when drained sand samples are tested [12, 27, 51]. Same behaviour is demonstrated by Omar and Sadrekarini [45] for undrained sand, while Lee [44] reports only an insignificant difference in strength between smooth and rough ends. According to some authors, the influence of ends on the internal friction angle is negligible $[13,16$, 50]; for others smooth ends imply lower friction angle $[27,45]$. While the majority of the studies support the use of smooth ends to guarantee stability and uniformity in failure, Olson and Campbell [13] notice how smooth ends do not decrease bulging effect. According to Duncan and Dunlop [48] smooth ends do improve the bulged shape but do not solve completely the non-uniform deformation. 
Discrepancies on lubrication effectiveness could be due to the fact that under pressure, especially on long term tests, the grease, if not enough viscous, is expelled out of its original place in contact with the end caps.

\section{Computer simulation}

The finite element method has made possible to reproduce experiments under the same conditions as in the laboratory. Additionally, it is possible to examine the stress and strain distribution and to predict the stress path of different points inside the triaxial sample. In fact, stress analysis proves a non-uniform distribution inside the sample during conventional laboratory tests [52].

Some laboratory tests were validated by FEM in the early 80's. For example, the non-homogeneous behaviour of clay samples was discussed by Carter [53] that used a modified Cam clay soil model, perfectly rigid and smooth ends and $\mathrm{H} / \mathrm{D}=2$ ratio. The effective stress is higher around the borders of the sample, while void ratio and pore pressure decrease moving from the inside to the outside. Same non-homogeneous stress and strain distribution in sample with $\mathrm{H} / \mathrm{D}=2$ was proved in other simulations. For example, Airey [54] supports the experimental tests proving that smooth ends can guarantee uniform conditions. Sheng et al. [55] identifies rough ends and insufficient drainage as two important causes behind the barrel shape. More non-uniformities in the axial and radial strains were found when rough ends were simulated instead of smooth ones. The importance of the drainage and the kind of end on the sample shape is stressed also by Liyanapathirana et al. [56]. The authors analyse tests with $\mathrm{H} / \mathrm{D}=2$ ratio and compare stresses and strains in the mid zone and next to the plate. It has been noted how all the points are on the same path only before the yielding surface. This implies that the non-uniform behaviour is negligible during elastic deformation. Yang $\&$ Ge [57] define 1/3 length in the middle of the sample as the area where the strains are uniform. In fact, in a fixed ends sample, the ends influence decreases with increasing distance away from the ends. The stress-strain curve is smoother for the points in this area. Jeremić et al. [58], analysing elastic-plastic sand samples with $H / D=2$, reported that as the end friction decreases, the stress-strain curve after yielding becomes flatter and more similar to the idealised constitutive behaviour of the soil. Consistent heterogeneities between upper and mid part of the sample are detected also on clay samples simulated in ABAQUS with $\mathrm{H} / \mathrm{D}=2$ and rough ends [59]. In fact, when at midheight of the sample large strain are detected, the area close to the ends is experiencing small strains. Same barrel shape in ABAQUS is demonstrated by Suebsuk et al. [60] Discrepancies in the stress distribution inside the sample are encountered also by using the software COSMOS/M [61]. It is shown that smooth ends decrease the yield stress of about $10 \%$ compared to rough ends. Moreover, for same stress and strain conditions, the angle of internal friction is $15 \%$ smaller when smooth ends are applied. Higher is the difference in cohesion, $42 \%$ smaller in samples with free ends.
Other few simulations study deeper the H/D ratio influence. Schanz and Gussman [62] idealised an isotropic linear elastic perfectly plastic soil material. Various $H / D$ ratios $(H / D=1,1.5,2$ and 4) were combined with different end frictions. The H/D ratio does not have any significant influence on the soil friction angle if $H / D \geq 2$. But for the lowest values of $H / D$, increasing the roughness of the plates causes higher values of soil friction angle. Also Ravaska [63] investigates different $\mathrm{H} / \mathrm{D}$ ratios $(\mathrm{H} / \mathrm{D}=0.5,1,2$ and 4$)$ using Plaxis. About drained tests on sand, there is no difference in friction angle between smooth or rough ends when $\mathrm{H} / \mathrm{D}>1.5$. When drained clay is tested, there is no difference in friction angle and in cohesion between smooth or rough ends when $\mathrm{H} / \mathrm{D}>1$.

Computer simulations support the laboratory observations on samples tested using rough ends and slenderness equal to $\mathrm{H} / \mathrm{D}=2$ (bulge shape, non-uniform deformation, less smooth stress-strain curve). The inhomogeneity inside the sample makes the external global measurements not representative of the true soil behaviour. Several simulations discussing the ends effect are found in the literature but not many results investigate the $\mathrm{H} / \mathrm{D}$ ratio influence.

\section{Conclusion}

The reliability of the triaxial tests with $H / D=2$ ratio and rough ends has been investigated and nowadays several studies support the use of samples with $\mathrm{H} / \mathrm{D}=1$ ratio and smooth ends $[4,8,15,23,29,38-40]$.

The majority of results associates the $H / D=1$ ratio and smooth ends with a more homogeneous stress-strain distribution and stable failure. A slenderness equal to $\mathrm{H} / \mathrm{D}=1$ is generally related to higher strength properties, while smooth ends imply lower friction angle. In the past, main focus of triaxial testing were the strength parameters, but now more attention is paid to volume and strain changes, observed to be higher at failure when $\mathrm{H} / \mathrm{D}=1$ ratio and smooth ends are employed.

The new research direction taken is the software simulation. FEM analyses validate many laboratory observations (i.e. non homogeneous stress-strain behaviour and barrel shape at mid height for the traditional sample, smoother stress-strain curve for smooth platens).

Considering that many studies do not present a wide test number and a one-by-one comparison for each factor of influence (H/D ratio and kind of ends), it is difficult to understand the separate effect of each of them.

\section{References}

1. K. L. Lee, F. J. J. Vernese, J Geotech Eng 104, 687 (1978)

2. D. W. Taylor, Seventh Prog. Rep. Triaxial Shear Strength (1941)

3. M. Jacobsen, Danish Geotech. Inst. 27, 7 (1970)

4. L. B. Ibsen, Soil Dyn. Earthq. Eng. 13, 63 (1994)

5. S. K. Nielsen, L. B. Ibsen, K. W. Sørensen, A. 
Shajarati, Proc. 23rd Int. Offshore Polar Eng., 518525, (2013)

6. T. Sabaliauskas, L. B. Ibsen, Geotech. Test. J. 41, 1117 (2018)

7. T. Sabaliauskas, L. B. Ibsen, ISOPE, 821-826 (2015)

8. T. Omar, A. Sadrekarimi, Int. J. Geotech. Eng. 6, (2015)

9. A. W. Bishop, D. J. Henkel, The Measurement of Soil Properties in the Triaxial Test (Edward Arnold, 1957)

10. K. H. Head, Manual of Soil Laboratory Testing : Effective Stress Tests (Pentech Press, 1986)

11. W. G. Shockley, R. G. Ahlvin, Res. Conf. Shear Strength Cohesive Soils, 341-357 (1960)

12. P. W. Rowe, L. Barden, J. Soil Mech. Found. Div. 90, 1 (1964)

13. R. E. Olson, L. M. Campbell, J. Soil Mech. Found. Div. 90, 167 (1964)

14. M. Roy, K. Y. Lo, Can. Geotech. J. 8, 579 (1971)

15. Poul V. Lade, Triaxial Testing of Soils (John Wiley \& Sons, 2016)

16. S. Goto, F. Tatsuoka, Adv. Triaxial Test. Soil Rock (ASTM International, 1988), 692-705

17. A. Balla, J. Soil Mech. Found. Div. 86, 57 (1960)

18. A. W. Bishop, G. E. Green, Géotechnique 15, 243 (1965)

19. L. B. Ibsen, P. V. Lade, AAU Geotech. Eng. Pap. Soil Mech. Pap. R 9908, (1999)

20. P. C. Rutledge, Cooperative Triaxial Shear Research Program of the Corps of Engineers (Waterways Experiment Station, 1947)

21. K. L. Lee, Influence of End Restraint in Cyclic Triaxial Tests (1976)

22. J. Desrues, E. Andò, F. A. Mevoli, L. Debove, G. Viggiani, Mech. Res. Commun. 92, 142 (2018)

23. J. L. J. Colliat-Dangus, J. Desrues, P. Foray, $A d v$. Triaxial Test. Soil Rock (ASTM International, 1988), 290-310

24. F. Tatsuoka, F. Molenkamp, T. Torii, T. Hino, Soils Found. 24, 113 (1984)

25. P. V. Lade, Q. Wang, Proc. NUMOG VIII (2002)

26. E. R. Moores, J. M. Hoover, Proc. Iowa Acad. Sci. (1966)

27. V. S. Raju, S. K. Sadasivan, M. Venkataraman, Soils Found. 12, 35 (1972)

28. B. Ladanyi, J. Arteau, Eng. Geol. 13, 207 (1979)

29. P. V. Lade, U. Wasif, Adv. Triaxial Test. Soil Rock (ASTM International, 1988), 706-714

30. P. V Lade, 11th Int. Conf. Soil Mech. Found. Eng., 549-552 ( 1985)

31. M. Jacobsen, Danish Geotech. Inst. 27, 21 (1970)

32. H. Güneyli, T. Rüşen, Bull. Eng. Geol. Environ. 75, 793 (2015)
33. A. H. Augustesen, J. S. Steenfelt, J. N. Goth, 17th Nord. Geotech. Meet, 309-318 (2016),

34. H. G. Larew, Res. Conf. Shear Strength Cohesive Soils, 1003 (1960)

35. P. W. Rowe, Proc. R. Soc. A Math. Phys. Eng. Sci. 269, 500 (1962)

36. G. E. Blight, J. Soil Mech. Found. Div. 3, 25 (1966).

37. H. Zhang, Steady State Behavior of Sands and Limitations of the Triaxial Tests, University of Ottawa, Canada (1997)

38. A. Dresher, I. Vardoulakis, Géotechnique 32, 291 (1982)

39. L. Barden, W. McDermott, J. Soil Mech. Found. Div. 91, 1 (1965)

40. L. Barden, A. J. Khayatt, Géotechnique 16, 338 (1966)

41. W. M. Kirkpatrick, D. J. Belshaw, Géotechnique 18, 336 (1968)

42. W. M. Kirkpatrick, J. S. Younger, J. Soil Mech. Found. Div. 1683 (1970)

43. W. M. Kirkpatrick, R. K. Seals, F. B. Newman, J Geotech Geoenviron Eng 100, 190 (1974)

44. K. L. Lee, J. Geotech. Eng Div. 104, 687 (1978)

45. T. Omar, A. Sadrekarimi, J. GeoEng. 9, 75 (2014)

46. A. S. Saada, F. C. Townsend, Lab. Shear Strength Soil A Symp. (ASTM STP 740, 1981), 7-77

47. A. Casagrande, S. J. Poulos, Fourth Report on Investigation of Stress-Deformation and Strength Characteristics of Compacted Clays (1964)

48. J. M. Duncan, P. Dunlop, J. Soil Mech. Found. Div. 94, 271 (1968)

49. A. Sachan, Indian Geotech. J. 41, 168 (2011)

50. T.-S. Ueng, Y.-M. Tzou, C.-J. Lee, Adv. Triaxial Test. Soil Rock (ASTM International, 1988), 679691

51. K. L. Lee, H. B. Seed, J. Soil Mech. Found. Div. 90, 173 (1964)

52. N. Verveckaite, J. Amsiejus, V. Stragys, J. Civ. Eng Manag., 63-70 (2007),

53. J. P. Carter, Géotechnique 32, 55 (1982)

54. D. W. Airey, Proc. 7th Int. Conf. Comput. Methods Adv. Geomech., 225-230 (1991)

55. D. Sheng, B. Westerberg, H. Mattsson, K. Axelsson, Comput. Geotech. 21, 163 (1997)

56. D. S. Liyanapathirana, J. P. Carter, D. W. Airey, Int. J. Geomech. 5, 10 (2005)

57. Q. Yang, J. Ge, Electron. J. Geotech. Eng. 17 F, 699 (2012)

58. B. Jeremić, Z. Yang, S. Sture, J. Eng. Mech. 130, 741 (2004)

59. D. Peric, S. Su, Proc. 16th Int. Conf. Soil Mech. Geotech. Eng., 571-574 (2005)

60. J. Suebsuk, S. Horpibulsuk, M. D. Liu, KSCE J. Civ. Eng. 20, 1300 (2016) 
61. N. Dirgèlienè, A. Norkus, J. Amšiejus, Š. Skuodis, D. Žilionienè, Balt. J. Road Bridg. Eng. 8, 25 (2013)

62. T. Schanz, P. Gussmann, Proc. 3rd Eur. Conf. Numer. Methods Geotech. Eng., 129-133 (1994),

63. O. Ravaska, Proc. 6th Eur. Conf. Numer. Methods Geotech. Eng., 161-165 (2006) 